\title{
RESEARCH
}

Open Access

\section{Posterolateral corpectomy with pyramesh titanium cage reconstruction in dorsolumbar metastatic lesions}

\author{
Ahmed Kamal Abdelhameid, Ahmed Saro ${ }^{*}$ (i) and Khaled Naser Fadl
}

\begin{abstract}
Background data: The vertebral column represents the most common bony site for metastasis with an incidence ranged from 30\% to $70 \%$ in patients with metastatic neoplasms. The dorsal spine carries the highest frequent site for metastasis all over the vertebral column followed by the lumber spine. These metastatic lesions are clinical entities that often necessitate a complex spinal decompression and anterior reconstruction. Posterolateral approaches alone allow for excellent decompression with transpedicular fixation and safe visualization of the neural elements for corpectomy and reconstruction so we can avoid the complications that can happen with the staged surgery.
\end{abstract}

Purpose: Our aim in the study is to report cases and evaluate our approach for fixation and assess the postoperative period regarding pain improvement and neurological deficit.

Study design: A retrospective study included 26 patients presented to the Neurosurgery Department at Sohag University Hospital within 3 years, between August 2014 and August 2017. Evaluation was made through using the Quebec Back Pain Disability Scale and muscle power grading scale.

Material and methods: Twenty-six patients with metastatic dorsolumbar spine lesions underwent a single -stage surgery by midline posterior approach. Posterior decompression with transpedicular fixation above and below the affected segment was done for all patients. Unilateral facetectomies and pediculectomy followed by corpectomy were done. Insertion of pyramesh titanium cage filled with iliac bone graft with tightness of the screws bilateral. Follow-up period was 6-12 months postoperatively.

Results: The average age was $58.36 \pm 5.96$ (range 33-67) years. More than two-thirds of them were males (69.2\%). Majority of the lesions were dorsal (77\%). Postoperative infection was observed in four patients (15.4\%) who improved by IV antibiotics and frequent dressing while CSF (cerebrospinal fluid) leak occurred in three patients (11.5\%) who stopped after daily dressing, and we made CSF lumbar tap in one patient. Twenty-two patients showed neurological improvement postoperatively (84.6\%). The remaining four were paraplegic with no improvement. Back pain improved for all cases.

Conclusion: Posterolateral approach alone is efficient and safe for dorsolumbar decompression and reconstruction in the metastatic spine.

Trial registration: IRB\#3747 registered on August 27, 2017

Keywords: Corpectomy, Pyramesh, Posterolateral, Pediculectomy, Facetectomies

\footnotetext{
* Correspondence: Ahmedsaro33@yahoo.com

Neurosurgery Department, Sohag Faculty of Medicine, Sohag, Egypt
} 


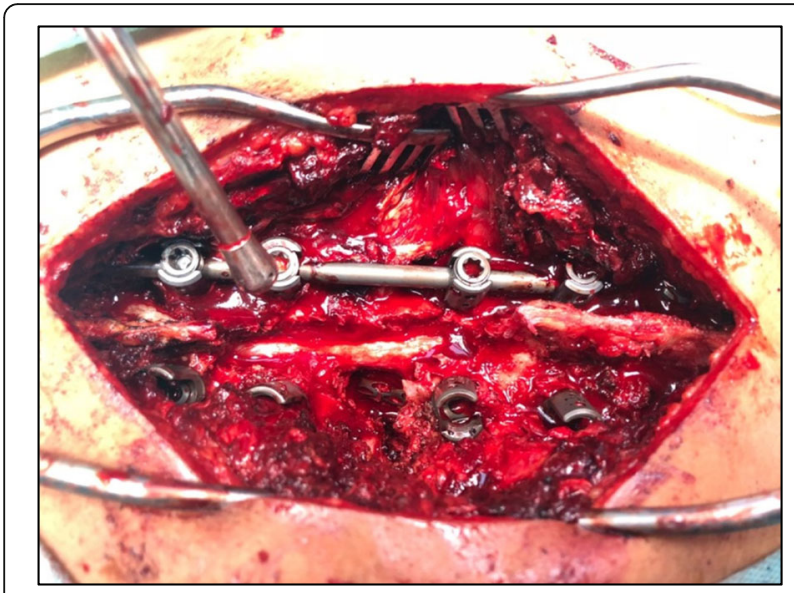

Fig. 1 Placement of the titanium pyramesh after corpectomy

\section{Introduction}

The vertebral column metastasis can contribute for about $30-70 \%$ of metastatic lesions in metastatic neoplasm patients so it is the most common site for bony metastases $[1,2]$. The dorsolumbar spine is the frequent site for metastasis and more than the cervical region, and lesions in this site often need a complex spinal decompression and reconstruction [3-5]. Traditionally, the dorsolumbar metastatic lesion surgeries necessitate combined approach or staged anterior and posterior decompression and fusion $[6,7]$.

Anterior approach carried the advantage of excellent visualization of the vertebral body and pathological condition; however, the possibilities of iatrogenic morbidity especially in critically ill patients make it a risky approach [8]. Posterolateral approaches appeared to have an excellent way for posterior decompression with

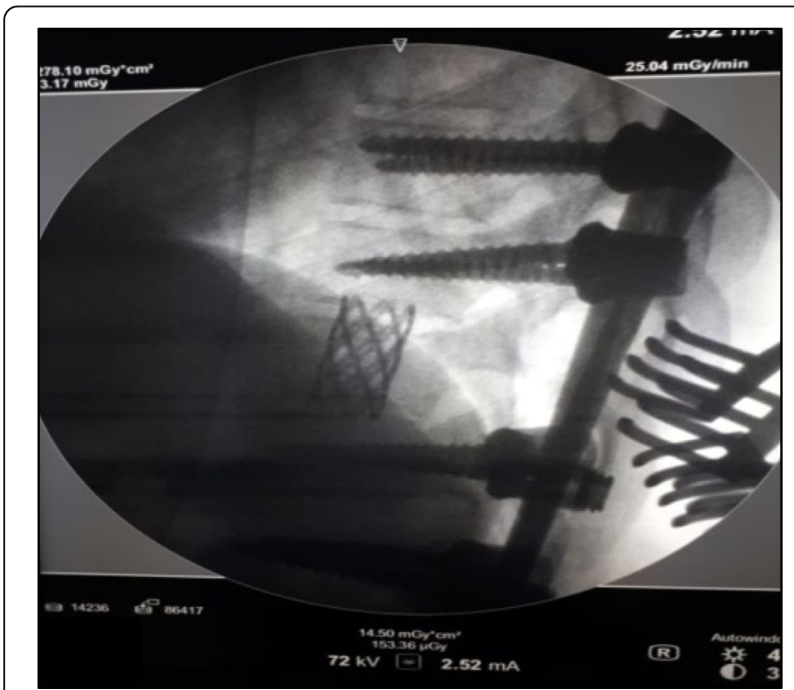

Fig. 2 Intraoperative fluoroscopy showing the placement of the pyramesh transpedicular screw fixation and in the same time allows for safe visualization of the neural elements with corpectomy and placement of a mesh cage $[4,7,9]$.

Our goal in this study is to report a clinical series of 26 patients in Sohag University Hospital with dorsolumbar metastatic lesions from different primaries treated by single-stage posterolateral circumferential corpectomy with reconstruction by a pyramesh titanium cage and account the degree of improvement regarding the pain.

\section{Patients and methods}

At the Neurosurgery Department in Sohag Faculty of Medicine, between August 2014 and August 2017, 26 patients with single dorsolumbar metastatic spinal lesions with vertebral body collapse underwent a singlestage, circumferential corpectomy and anterior spinal reconstruction with a pyramesh titanium cage via a midline, posterior, and lateral approach.

We included in our study patients with retropulsed fragment inside the canal that causes spinal cord compression with neurological manifestation in patients with expected life span of more than 1 year. Metastatic workup was done for our cases. Exclusion criteria include patients with more than one spinal metastasis or extra-spinal metastasis, patients with other comorbidities as cardiac ill patients, patients with chronic renal failure, and patients who received radiotherapy or chemotherapy within 1 year before surgery. In a preoperative neurological assessment, full laboratory investigations were done. We used the Quebec scale to assess the patients' improvement regarding pain, and muscle power scale to evaluate the motor power improvement.

\section{Operative technique}

Under general anesthesia with hypotensive anesthesia technique, our patients were placed prone in radiolucent spine frame that allows for intraoperative AP (anteroposterior) and lateral imaging by $\mathrm{C}$-arm. A standard midline posterior skin incision is done with subperiosteal dissection above and below the affected level. Cauterization was done for the bleeding points.

In the majority of our cases, transpedicular screws were placed bilaterally two levels above and two levels below the involved vertebra. However, in one case, we noticed a high level of wedged vertebrae with osteoporotic bone, so we lengthened the fixation levels in this patient. A rod is placed unilaterally contralateral to the side planed for pediculectomy and corpectomy, and gentle distraction is applied for stabilization of the spine during the manipulation for corpectomy.

At the affected vertebrae, laminectomy is carried out with the removal of the facet and then skeletonizing pedicle. Only laminectomy with facetectomies can be 


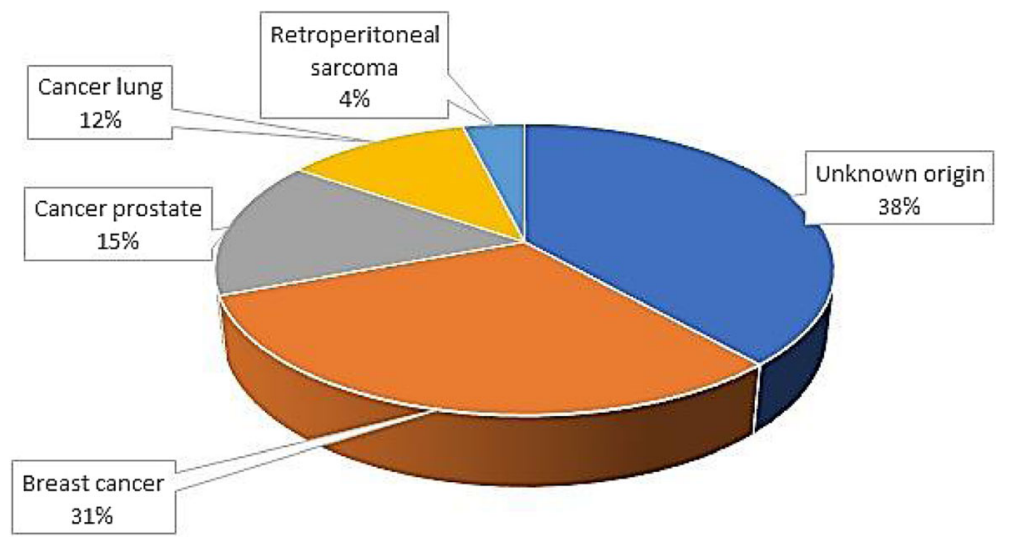

Fig. 3 Origin of metastasis

done in one level above and below the affected vertebra to maximize the cephalic caudal working space between the nerve roots, which becomes critical during the pyramesh cage placement. At the dorsal spine lesions, we can sacrifice with the nerve root by ligation and bipolar cauterization to decrease the possibility of CSF leak.

At the aimed level, the transverse process is resected using a Kerrison rongeur and then exposed the lateral edge of the vertebral body. In the dorsal spine, disarticulation of the transverse process from the ribs should be done first. Subperiosteal dissection was performed using the Cobb. Packing sponge was applied very gently and slowly around the vertebral body to avoid the potential vascular, pleural, or peritoneal injury. A high-speed burr was then used cautiously to drill the pedicle and the vertebral body away from the exiting nerve root and the spinal cord.

Curettes were used to perform the discectomy above and below the involved vertebrae. If the vertebral body was completely destructed, we went for bilateral corpectomy, but if the lesion was unilateral, we performed a unilateral pediculectomy, discectomies, and corpectomy till the creation of an eggshell hole leaving the other side that augments the posterolateral fusion bed. Dorsal cortex should be preserved to minimize the epidural bleeding and protection of the spinal cord. Once the discectomies are completed, the vertebral body is hollowed using the high-speed burr and curved curettes.

Table 1 Assessment of pain on daily activities using the Quebec scale among our patients

\begin{tabular}{lll}
\hline Quebec scale & Preoperative & Postoperative \\
\hline Severe (98-80) & 14 & 10 \\
Moderate (40-79) & 7 & 5 \\
Mild (below 40) & 5 & 11
\end{tabular}

Paired $t$ test $=8.742 ; P$ value $<0.001$ (highly significant)
The most challenging part of the procedure occurs with the pyramesh cage placement. Firstly, we measure the length of the suitable cage and filled with iliac crest bone graft.

Placement of the cage should be parallel to the nerve root with gentle retraction of the root. Once we entered the cage inside the corpectomy hole, we rotate it $90^{\circ}$ until it is perpendicular to the adjacent vertebral endplates (Fig. 1).

Distraction was then performed under direct fluoroscopy with very gentle modulation of the cage to reach its appropriate position against the vertebral endplates without tilting (Fig. 2).

Finally, we placed the second rod with loosening of the first rod screws to make bilateral compression across the affected segments. All of the set screws were tightened and additional bone graft was then packed around the posterolateral contralateral side.

\section{Statistical analysis}

Data was analyzed using Microsoft Excel 2016 (Microsoft corporation, USA) and SPSS version 24 (May 2016, IBM corporation, USA). Qualitative data was presented as numbers and percentages, while quantitative data were presented as mean and standard deviation. Comparison between pre- and postoperative data regarding the Quebec scale and motor power was done using a paired $t$ test. $P$ value of less than 0.05 was considered significant.

\section{Results}

Twenty-six patients were operated with metastatic dorsolumbar lesions with a predominance of male ratio.

Our patient's age ranged from 33-67 years with a mean of $58.36 \pm 5.96$ years. In our study, the dorsal metastatic lesions were more predominant that account for 20 cases. On the other hand, the lumbar metastatic lesions were only six cases. 


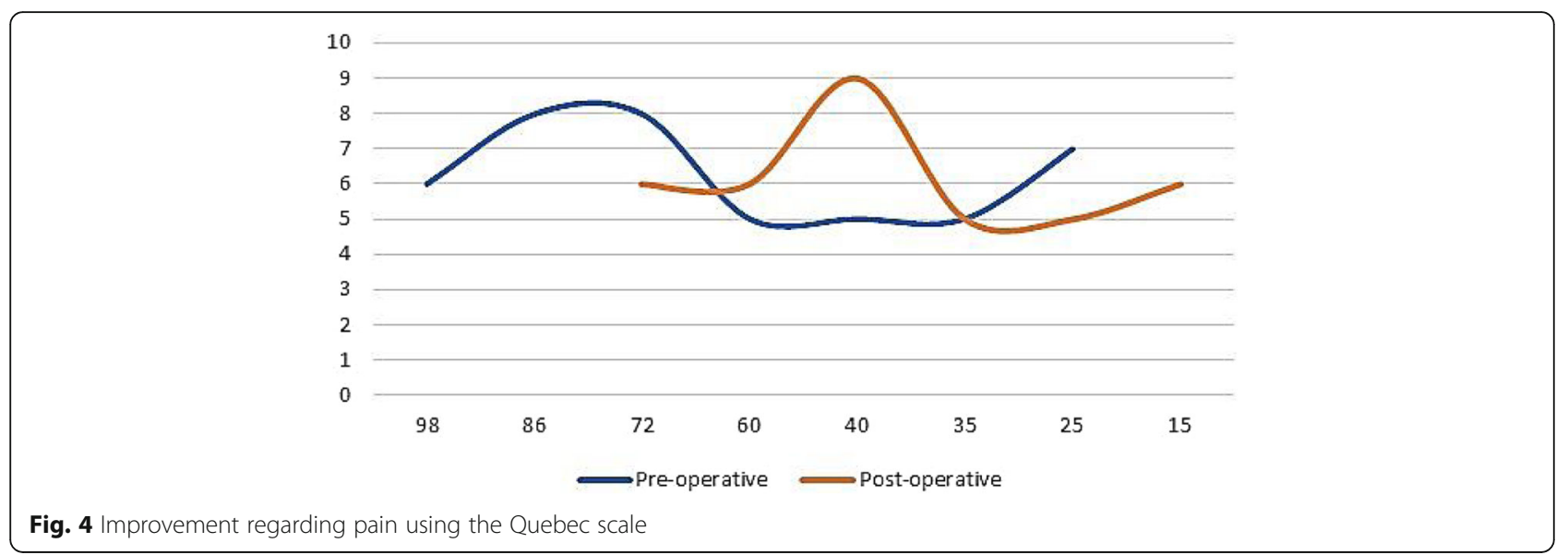

Metastasis of unknown origin was reported in 10 patients. Postoperative histopathology showed they were adenocarcinomas from the colon, stomach, and kidney, and breast cancer was responsible for eight cases, four cases with prostatic cancer, three cases with small cell lung cancer, and the last case was with retroperitoneal sarcoma (Fig. 3).

Back pain was the main complaint for all our patients and we use the Quebec Back Pain Disability Scale for pre- and postoperative assessment (Table 1 and Fig. 4).

Six patients were paraplegic grade zero more than 10 days preoperative. Improvement in the motor power occurred in two of them while the remaining four did not improve, but the sensation regained and the back pain improved (Table 2). In four cases, iatrogenic dural tear happened and repair was done simply. Three patients presented by postoperative CSF leak and stopped within 4 weeks after limitation of movement and medication. Superficial wound infection was noted in four cases which resolved with broad-spectrum antibiotics and daily dressings (Table 3 ).

\section{Discussion}

Spinal metastasis is the most commonly encountered tumor of the spine [10] , occurring in more than $40 \%$ of

Table 2 Preoperative and postoperative muscle power state

\begin{tabular}{lllll}
\hline Preoperative & & & Postoperative & \\
\cline { 1 - 1 } \cline { 5 - 5 } Motor power & No. & & Motor power & No. \\
\hline Complete paraplegia & 6 & & Complete paraplegia & 4 \\
Grade I & 7 & & Grade I & 0 \\
Grade II & 2 & & Grade II & 0 \\
Grade III & 5 & & Grade III & 3 \\
Grade IV & 6 & & Grade IV & 10 \\
Grade V & 0 & & Grade V & 9 \\
\hline
\end{tabular}

Paired $t$ test $=7.939, p$ value $<0.001$ (highly significant) patients with cancer. Each year, 5\% of patients with cancer will develop spinal metastasis [11].

Breast cancer comes in the first place of causes of spinal metastasis (21\%) (Fig. 5), followed by lung cancer $(14 \%)$. Dorsal spine is the commonest site for metastatic affection, then lumbar region, and finally the cervical spine which is less frequent. Spinal metastasis can cause instability either by the destruction of the bony element or by pathological fracture which can occur under normal physiologic stress [12].

Partial or total destruction of the anterior vertebral body results in decreased load-bearing capacity of the spine and mostly resulted in spinal cord compression that needs decompression, fixation, and anterior reconstruction $[10,13]$. Traditionally, these pathological conditions have been treated by a staged anterior and posterior decompression and fusion with a high risk for morbidity and mortality due to an anterior approach in generally ill patients (Figs. 6, 7, 8, 9, 10, 11, 12) [12, 14].

In 1976, Larson and his colleagues described the lateral extracavitary approach. The difficulty of the spinal reconstruction due to the unique anatomy of the lumbar spine with the association of increased blood loss and poor visualization across the midline has limited its widespread acceptance [15-17].

The extent of visualization is debatable and depends on the surgeon, but with using the magnifying loops or microscope in most cases, a unilateral

Table 3 Postoperative complications in our series

\begin{tabular}{lll}
\hline Postoperative complications & No. of patients & Percentage \\
\hline Dural tear & 4 & $15.4 \%$ \\
Superficial wound infection & 4 & $15.4 \%$ \\
CSF leak & 3 & $11.5 \%$ \\
Pleural injury & 0 & $0.0 \%$ \\
Vascular injury & 0 & $0.0 \%$ \\
Neurological deterioration & 0 & $0.0 \%$ \\
\hline
\end{tabular}




\section{Case (1)}
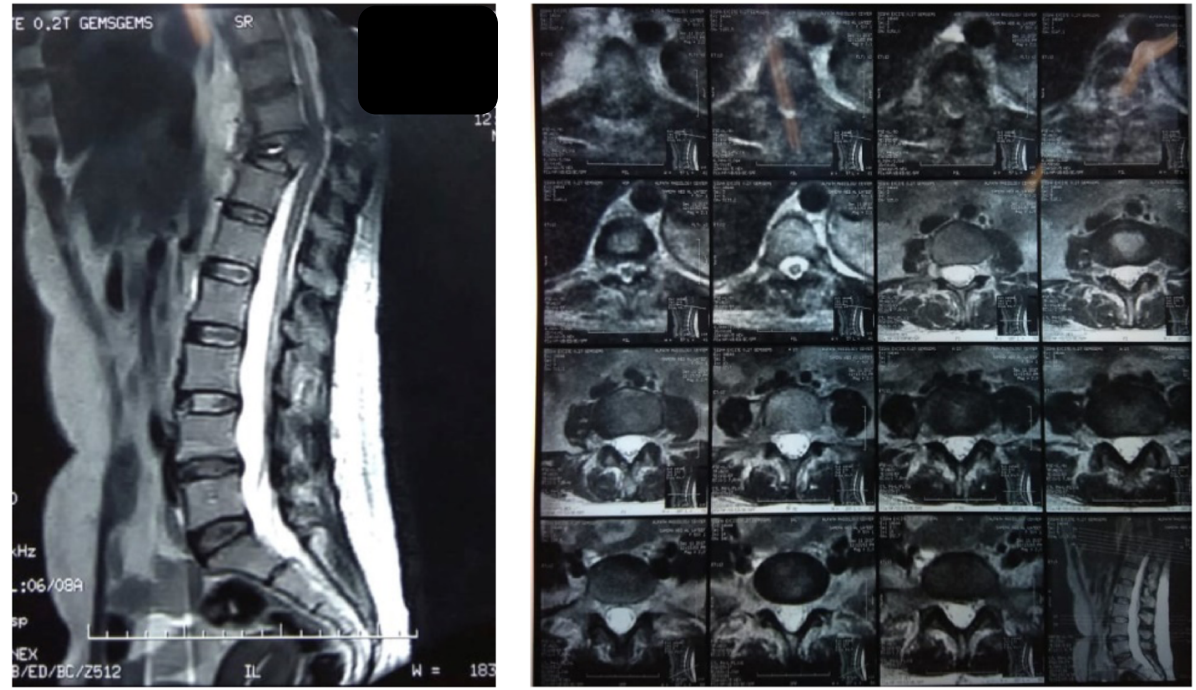

Fig. $5 \mathrm{MRl}$ of the dorsolumbar spine shows complete destruction of dorsal 11 in metastatic 47-year-old female with known history of breast cancer

approach may be performed safely to the contralateral pedicle with good visualization. A bilateral approach is appropriate in situations of primary malignancy or solitary metastatic disease where an en bloc spondylectomy is advisable. Blood loss can be minimized by skeletonizing the pedicle with resection of the transverse process, putting gelfom and surgicell in the lateral border of the vertebral body also by leaving the ventral cortex which provides us by a safe zone from epidural veins bleedings [18].

Still sacrificing the nerve root intraoperatively in lumbar region is a common surgical choice for placing the pyramesh, but we can avoid this by gently placing the root caudly and then we enter with the pyramesh parallel to the root and rotate it inside the corpectomy hole. In dorsal lesions, we can sacrifice the root by ligation and bipolar diathermy. Recently, with the advent of expandable metallic cages, allposterior spinal reconstruction can be accomplished without sacrificing the lumbar spinal nerve roots. Hunt and colleagues described the use of an expandable cage in a single patient [16].

Leaving the ventral cortex after drilling the vertebral body provides us with the advantage of keeping both the spinal cord and the epidural veins away from intraoperative iatrogenic injury. Also, the slow
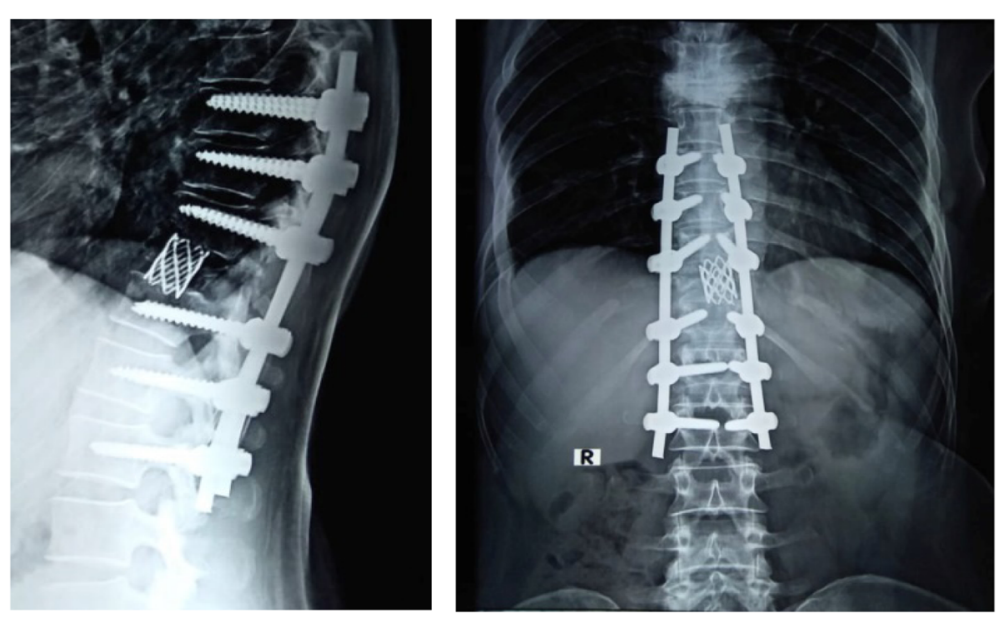

Fig. 6 Six months of postoperative $X$-ray follow-up 


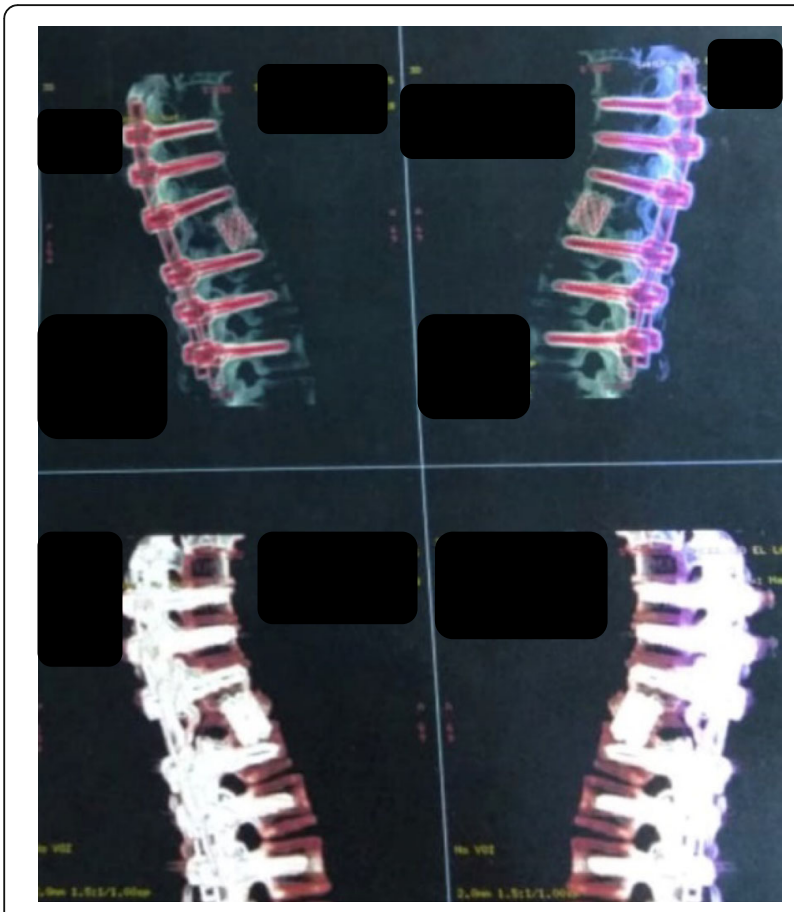

Fig. $73 D C T$ follow-up 6 months postoperative

dissection through the lateral border of the vertebral body by the packing sponge protects the intra-abdominal vascular injury in the lumbar spine or the pleural injury in the dorsal spine [19].

Most authors agreed for transpedicular fixation of two levels above and two levels below the affected segment, but we can modulate this according to the quality of bone and if there is abnormalities along the spine in another segment or not [9]. In our study, we found a case with wedged vertebrae above the affected segment and this push us to lengthen the fixation segment.

Reduction in the operative time and avoidance of staged surgery with its morbidity and surgical blood

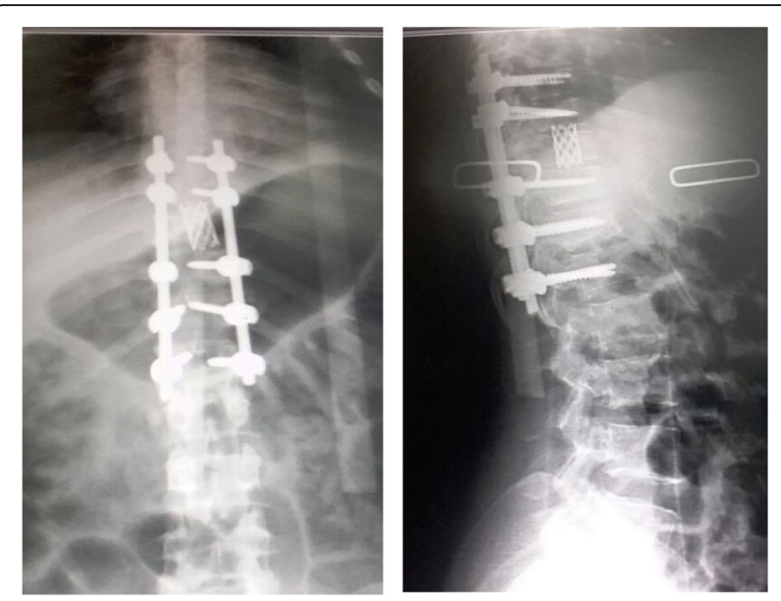

Fig. 9 Postoperative X-ray AP and lateral after decompression with pyramesh cage reconstruction (case 2)

loss give advance to the posterolateral approach. So, a single-staged lumbar extracavitary corpectomy and circumferential reconstruction should be a part of every spine surgeon's armamentarium [20].

Recent advances in treatment options of spinal metastasis include minimally invasive approaches and radiosurgery which control the local tumor recurrence after separation surgeries, where surgery separate tumors from neural elements [21].

\section{Conclusion}

Posterolateral corpectomy and reconstruction approach in the management of metastatic dorsolumbar spine lesions with destruction of the vertebral body are effective and safe surgical approach with less time and minimal blood. All patients improved in back pain while most of them improved regarding the neurological deficit. A larger study advised for more evaluation and exposing complications.

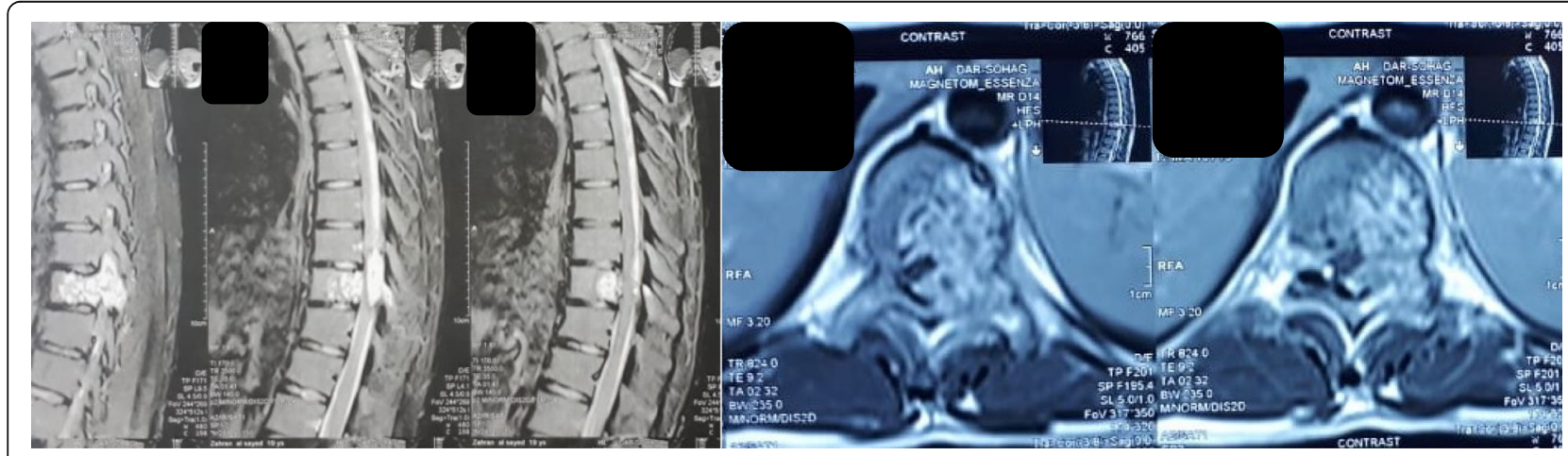

Fig. $8 \mathrm{MRI}$ of the dorsal spine showing the effect of dorsal 10 

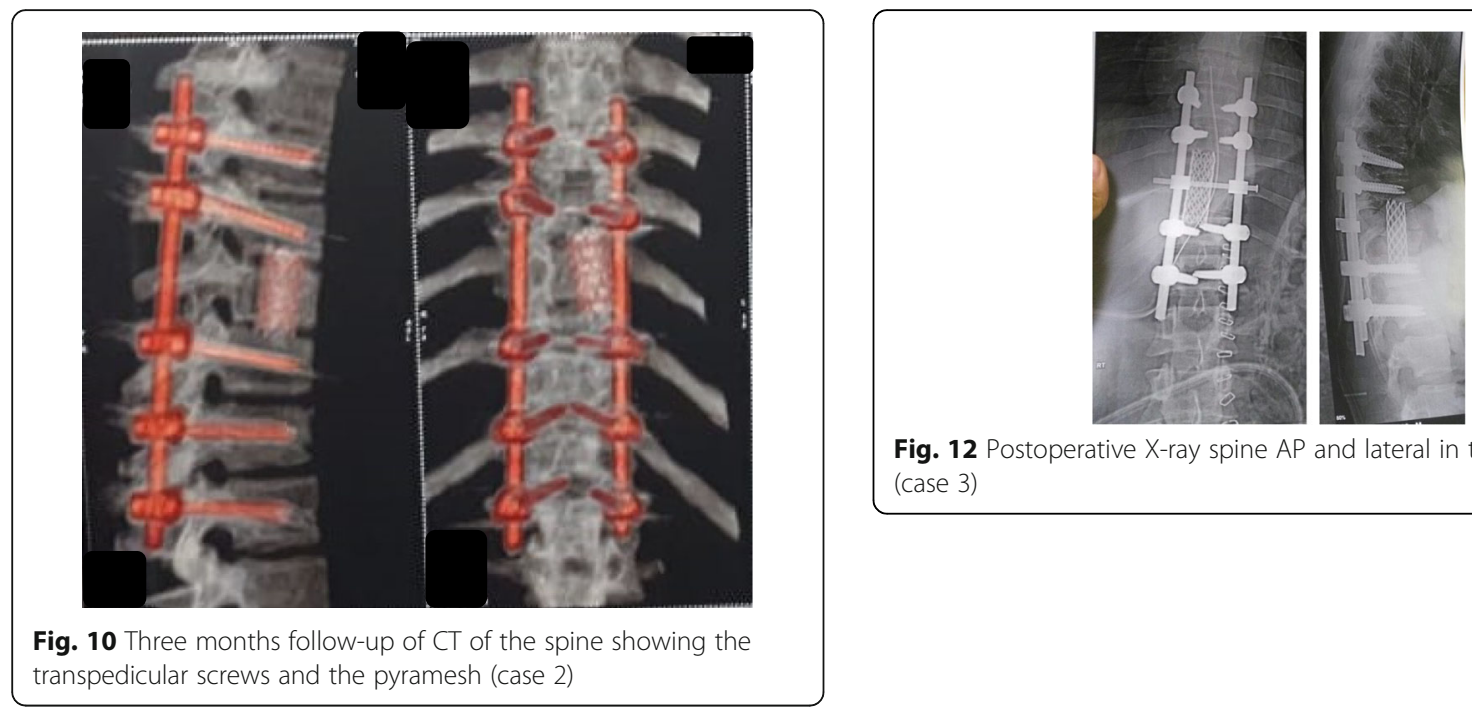

Fig. 12 Postoperative $X$-ray spine AP and lateral in the same patient (case 3)

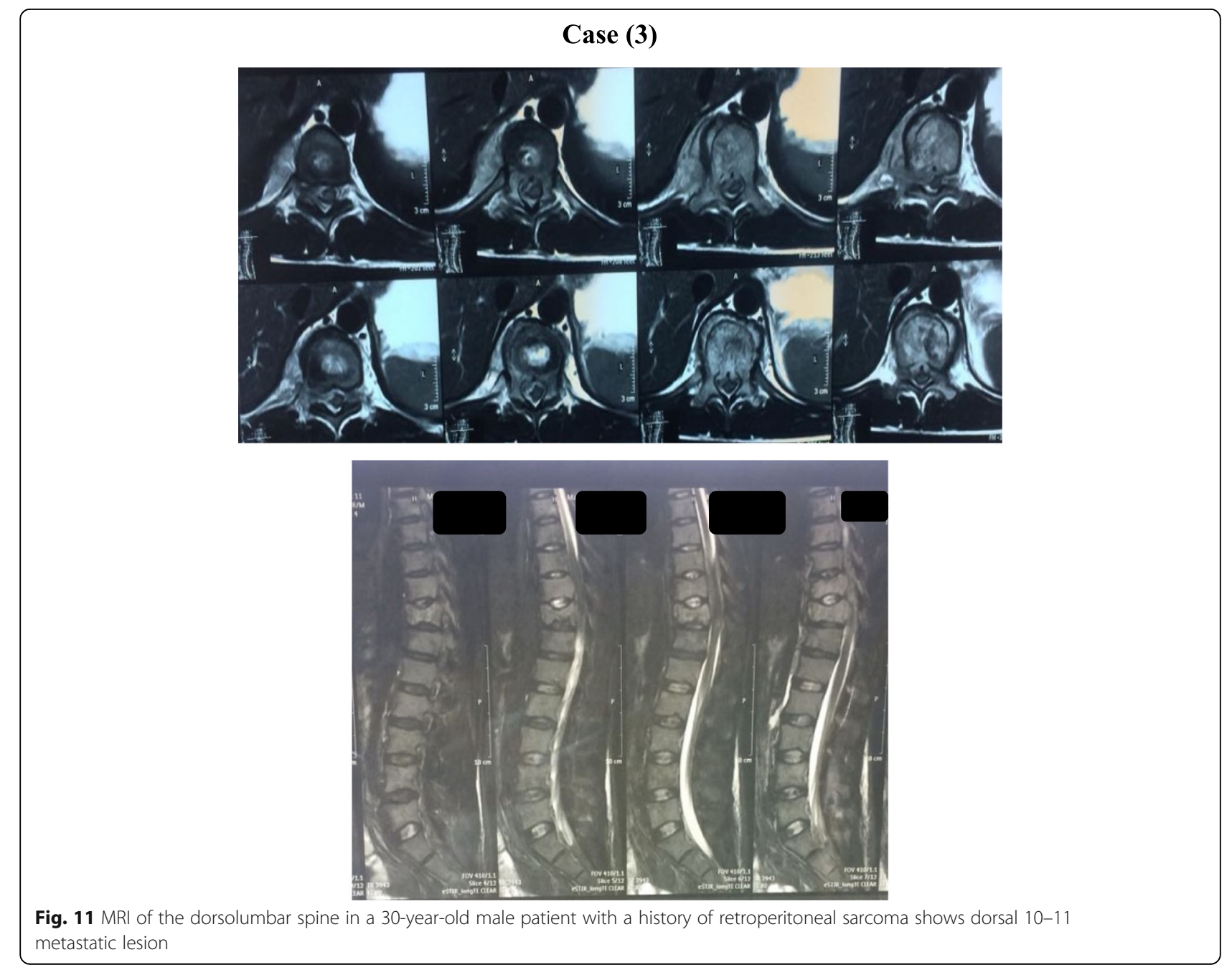




\section{Abbreviations}

AP: Anteroposterior; CSF: Cerebrospinal fluid

\section{Acknowledgement}

The authors would like to thank the whole members of neurosurgery department for allowing us to analyze traumatized patients data for this study.

\section{Authors' contributions}

AKA gave the idea and collected the patients' data and analyze them. AS put the study design and followed the patients postoperatively. KNF wrote the paper with revision. They all approved the final version of the manuscript. They all have agreed both to be personally accountable for the author's own contributions and to ensure the questions related to the accuracy or integrity of any part of the work.

\section{Funding}

None

\section{Availability of data and materials}

The datasets used and/or analyzed during the current study are available from the corresponding author on reasonable request.

\section{Ethics approval and consent to participate}

We had approval from the local ethical committee concerning aspects of medical research. All cases included in this had signed informed written consent to participate in this research and to publish the data before being included in the study (signed by a first-degree relative in non-fully conscious patients).

The ethical committee of the Faculty of Medicine, Sohag University, Egypt, approved this research prior to starting it, 57/2015 (reference email, emmedicine@sohag.edu.eg; reference phone number, +2-093-4573124).

\section{Consent for publication}

All cases included in this had signed informed written consent to publish the data

\section{Competing interests}

The authors declare that they have no competing interests.

Received: 26 November 2018 Accepted: 15 July 2019

Published online: 24 July 2019

\section{References}

1. Bhardwaj P, Bhardwaj N. Motor grading of elbow flexion - is Medical Research Council grading good enough? J Brachial Plex Peripher Nerve Inj. 2009;13:40-3.

2. Bianchi C, Ballard JL, Abou-Zamzam AM, Teruya TH, Abu-Assal ML. Anterior retroperitoneal lumbosacral spine exposure: operative technique and results. Ann Vasc Surg. 2003;17(2):137-42.

3. Harrington KD. Metastatic disease of the spine. J Bone Joint Surg Am. 1986;68:1110-5.

4. Hunt T, Shen FH, Arlet V. Expandable cage placement via a posterolateral approach in lumbar spine reconstructions. Technical note. J Neurosurg Spine (Phila Pa 1976). 2006:5(3):271-4.

5. Jacobs WB, Perrin RG. Evaluation and treatment of spinal metastases: an overview. Neurosurg Focus. 2001:11(article 1):1-11.

6. Singh K, Park DK. Lumbar extracavitary corpectomy with a single stage circumferential arthrodesis: surgical technique and clinical series. Am J Orthopedics. 2012;7(2):316-20.

7. Klimo P Jr, Dailey AT, Fessler RG. Posterior surgical approaches and outcomes in metastatic spine disease. Neurosurg Clin N Am. 2004;15(4):425435.

8. Klimo P Jr, Schmidt MH. Surgical management of spinal metastases. Oncologist. 2004;9:188-96.

9. Krishnaney AA, Steinmetz MP, Benzel EC. Biomechanics of metastatic spine cancer. Neurosurg Clin N Am. 2004;15:375-80.

10. North RB, LaRocca VR, Schwartz J, North CA, Zahurak M, Davis RF, McAfee PC. Surgical management of spinal metastases: analysis of prognostic factors during a 10-year experience. J Neurosurg Spine. 2005;2(5):564-73.
11. Oda I, Cunningham BW, Abumi K, Kaneda K, McAfee PC. The stability of reconstruction methods after thoracolumbar total spondylectomy. An in vitro investigation. Spine. 1999;24(16):1634-8.

12. Uei H, Tokuhashi $Y$, Maseda M. Treatment outcome of metastatic spine tumor in lung cancer patients: did the treatments improve their outcomes? Spine (Phila Pa 1976). 2017:42(24):E1446-51.

13. Riaz S, Fox R, Lavoie MV, Mahood JK. Vertebral body reconstruction for thoracolumbar spinal metastasis--a review of techniques. J Ayub Med Coll Abbottabad. 2006;18(1):70-7.

14. Sakaura H, Hosono N, Mukai Y, Ishii T, Yonenobu K, Yoshikawa H. Outcome of total en bloc spondylectomy for solitary metastasis of the thoracolumbar spine. J Spinal Disord Tech. 2004;17(4):297-300.

15. Samartzis D, Foster WC, Padgett D, Shen FH. Giant cell tumor of the lumbar spine: operative management via spondylectomy and shortsegment, 3column reconstruction with pedicle recreation. Surg Neurol. 2008;69(2):138-41.

16. Schmidt MH, Larson SJ, Maiman DJ. The lateral extracavitary approach to the thoracic and lumbar spine. Neurosurg Clin N Am. 2004;15(4):437-41.

17. Senel A, Kaya AH, Kuruoglu E, Celik F. Circumferential stabilization with ghost screwing after posterior resection of spinal metastases via transpedicular route. Neurosurg Rev. 2007;30(2):131-7.

18. Snell BE, Nasr FF, Wolfla CE. Single-stage thoracolumbar vertebrectomy with circumferential reconstruction and arthrodesis: surgical technique and results in 15 patients. Neurosurgery. 2006;58(4 Suppl 2):ONS-263-268.

19. Windhagen HJ, Hipp JA, Silva MJ, Lipson SJ, Hayes WC. Predicting failure of thoracic vertebrae with simulated and actual metastatic defects. Clin Orthop Relat Res. 1997:(344):313-9.

20. Wong DA, Fornasier VL, MacNab I. Spinal metastases: the obvious, the occult, and the impostors. Spine. 1990;15:1-4.

21. Zuckerman SL, Laufer I, Sahgal A, Yamada YJ, Schmidt MH, Chou D, Shin JH, Kumar N, Sciubba DM. When less is more: the indications for MIS techniques and separation surgery in metastatic spine disease. Spine (Phila Pa 1976). 2016;41 Suppl 20:\$246-53 Review.

\section{Publisher's Note}

Springer Nature remains neutral with regard to jurisdictional claims in published maps and institutional affiliations.

\section{Submit your manuscript to a SpringerOpen ${ }^{\circ}$ journal and benefit from:}

- Convenient online submission

- Rigorous peer review

- Open access: articles freely available online

- High visibility within the field

- Retaining the copyright to your article

Submit your next manuscript at $\boldsymbol{\nabla}$ springeropen.com 